\title{
Life Effects of Narcolepsy in 180 Patients from North America, Asia and Europe Compared to Matched Controls
}

\author{
ROGER BROUGHTON, QUAIS GHANEM, YASUO HISHIKAWA, YOSHIRO SUGITA, \\ SONIA NEVSIMALOVA and BEDRICH ROTH
}

\begin{abstract}
SUMMARY: A questionnaire survey has been made of the life effects of narcolepsy in 180 patients, 60 each from North American, Asian and European populations, with 180 similarly distributed age and sex matched controls. Life-effects were attributed by the patients to the primary symptoms of excessive daytime drowsiness, sleep attacks, cataplexy, vivid hypnagogic hallucinations and sleep paralysis, and also to other frequent symptoms such as visual problems (blurring, diplopia) and memory impairment. Occupational problems were prevalent (over $75 \%$ ) and included statistically significant deleterious effects upon performance, promotion, earning capacity, fear of or actual job loss
\end{abstract}

RÉSUMÉ: Nous avons étudié par questionnaire les effets sur la vie de 180 patients souffrant de narcolepsie ( 60 d' Amérique du Nord, 60 d'Asie et 60 d'Europe) et de 180 témoins apparillés pour âge et sexe. Parmi les causes importants mentionnées par les patients, on note la somnolence diurne excessive, les attaques de sommeil, la cataplexie, les hallucinations hypnagogiques vivides et la paralysie du sommeil. D'autres symptômes fréquents furent les problèmes visuels et les pertes de mémoire. Des problèmes au travail etaient trés fréquents $(75 \%)$ et significativement influent sur la performance, les promotions, la capacité à gagner, la crainte de la perte and increased disability insurance. Driving was greatly affected and patients fell asleep at the wheel more frequently (66\%), had near or actual accidents from drowsiness or falling asleep at the wheel (67\%), and could experience cataplexy (29\%) or sleep paralysis (12\%) while driving. Work or home accidents attributed to sleepiness or sleep $(49 \%)$ or related to smoking $(49 \%)$ were much more common in patients. There were also deleterious effects on education, recreation and personality related to the disease. Narcolepsy can produce a variety of life-effects probably more serious and pervasive than, for instance, those of epilepsy, therefore emphasizing the importance of early diagnosis and treatment.

d'emploi ou la perte réelle de l'emploi et l'assurance invalidité. La conduite d'un véhicule moteur était souvent difficile; endormissement à la roue (66\%), accidents après somnolence (67\%), cataplexie (29\%) ou paralysie du sommeil (12\%) avec le véhicule en marche. Les accidents à la maison ou au travail étaient également plus fréquents, en rapport avec le sommeil (49\%) ou le fait de fumer (49\%). La narcolepsie eut également des effets nocifs sur l'éducation, la récréation et la personalité. La narcolepsie est donc apte à causer de nombreux problèmes, ce qui devrait inciter à faire le diagnostic tôt pour entreprendre rapidement le traitement.
From the Division of Neurology, University of Ottawa (Canada), Department of Neuropsychiatry, University of Osaka (Japan), and Neurology Clinic, Charles University, Prague (Czechoslovakia).

Reprint requests to: Dr. R. Brought on, Division of Neurology, Ottawa General Hospital, 501 Smyth Rd., Ottawa, Ontario, Canada K1H 8 L6.

\section{INTRODUCTION}

The major symptoms of narcolepsy, especially the irresistible sleep attacks, chronic daytime drowsiness and cataplectic attacks can have marked deleterious effects on socio-economic and other aspects of everyday life. Although some early publications, such as that of Daniels (1934), gave some emphasis to these effects, recent literature has concentrated on other aspects of the condition. The only direct studies of these are a report comparing driving in narcoleptics to controls (Bartels and Kusakcioglu, 1955), mention of the frequency of some life effects by Passouant and Billiard (1976), and a controlled study of 43 patients with narcolepsy-cataplexy compared to matched normals by Broughton and Ghanem (1976). The present report represents an extension of the latter study to an international project involving three cultural groups. Additional details may be found in the proceedings of a recent congress on sleep research (Broughton et al., 1981).

\section{METHODS AND PATIENTS}

Data were gathered using the two questionnaires (available from authors upon request) from the previous lifeeffects study of Broughton and Ghanem (1976). The one for narcoleptics contains over 160 items enquiring into effects on work, education, driving, occupational and household accidents, recreation, personality and interpersonal relationships, plus the presence or absence of numerous symptoms other than sleep attacks and cataplexy, which might also affect socio-economic variables. These include visual problems, memory difficulties, changes in appetite and sexual activity, and miscellaneous somatic symptoms. An otherwise identical questionnaire for 
the controls had the word "sleepiness" substituted for "narcolepsy symptoms". The questionnaires were translated into Japanese and Czech at the collaborating centers. At each centre they were completed by 60 patients and 60 local normal controls matched for sex and age (within a year). Each questionnaire was checked for omissions and ambiguous responses by the co-authors at the center involved before being sent to Ottawa for statistical analysis.

Thus, there were 180 narcoleptics and 180 matched controls divided evenly amongst the three centers. Both major cohorts comprised 112 males and 68 females, with an age range of 15-71 years. The narcoleptics' mean age was $41.9 \pm 11.3$ years and that of the controls $41.9 \pm 11.4$ years. There were no significant differences between the three cultural populations in age or marital status. All narcoleptics had either excessive daytime sleepiness $(\mathrm{N}=172$, i.e., $95.6 \%)$ or actual sleep attacks (166, i.e., 92.2\%) plus one or more of the REM based auxiliary symptoms: cataplexy in $162(90 \%)$, sleep paralysis in $85(47.2 \%)$, and vivid hypnagogic hallucinations in $85(47.2 \%)$. One hundred and nineteen patients (66.1\%) also complained of restless night sleep. In comparison, some controls also experienced a restless night sleep (38, i.e., $21.1 \%$ ), excessive drowsiness (35, i.e., $19.4 \%$ ), or vivid imagery on falling asleep $(7$, i.e., $3.9 \%)$. Five $(2.7 \%)$ had had sleep paralysis at least once; and $3(1.7 \%)$ actually noted episodes of some degree of weakness with emotional stimuli. None, however, were considered definitely narcoleptic.

The narcoleptics' medication included methylphenidate in 63 patients, amphetamines in 21 , ephedrine in 6 , phenmetrazine in 6 , and dexphenmetrazine in two. These stimulants were supplemented by $4.5 \pm 2.5$ cups of tea or coffee per day. Anti-depressant medication used for its REM-suppressant action included tricyclic drugs in 59 patients, and MAO inhibitors in two. Hypnotics and tranquillizers were being taken by 31 patients; and 20 were not receiving any $\mathrm{CNS}$ active drugs.

Almost all life-effect questions in the questionnaires entailed a "yes", "no", or "don't know" answer. Statistical comparisons were made for all positive answers for each item between the pooled 180 narcoleptics and the 180 controls using the equation for differences of proportions (Spiegel, 1961). Because of the large number of comparisons, the significance level was set conservatively at $p<.002$. In the following text all items were significantly different at that level, unless specifically noted to be non-significant (NS).

\section{Work \\ RESULTS}

There was a variety of similar jobs in the two groups which included professionals, clerical workers, technologists, labourers, housewives and students. As shown in Table 1, working narcoleptics had a much higher incidence of symptoms leading to deterioration of all occupational variables. Amongst the 148 working narcoleptics, difficulties with jobs were attributed to sleep attacks in $140(94.6 \%)$, inability to concentrate in $63(42.6 \%)$, memory problems in $46(31.2 \%)$, interpersonal problems in $35(23.6 \%)$, and personality changes in $26(17.6 \%)$. These figures were significantly higher than the corresponding ones for the 172 working controls, which were 2 $(1.2 \%), 16(9.3 \%), 19(11.0 \%), 20$ $(11.6 \%)$, and $1(0.6 \%)$, respectively. The nature of the work difficulties varied from the trivial to the serious

including, for example, falling asleep while manipulating heavy machinery.

\section{Education}

Among narcoleptics, 76 (42.2\%) stated that their symptoms began before their formal education was over, whereas excessive sleepiness was present at that time in $5(3.0 \%)$ of the controls. The patients believed that the symptoms caused poor marks in 39 $(51.3 \%)$, interpersonal problems with teachers in $26(34.2 \%)$, and embarrassment in $24(31.5 \%)$. Each of the three was noted in only one of the controls. Never-the-less, there were no significant differences between narcoleptics and controls in the proportion that had reached public school, high school or an equivalent, or university. The corresponding figures for each level of education were $169(93.9 \%)$ in patients versus $170(94.8 \%), 116(64.8 \%)$ versus $142(78.9 \%)$, and $52(29.1 \%)$ versus 68 $(37.8 \%)$. The less frequent attainment of university education in narcoleptics, however, almost reached significance (p>.002 and <.05).

\section{Driving}

A comparison of driving between the two groups is presented in Table 2 . Of the 32 patients whose symptoms led to accidents, $9(28.0 \%)$ were considered serious. Subjects were asked to describe their worst accidents attributable to their narcolepsy symptoms.

TABLE 1

Occupational effects attributed to narcolepsy symptoms in working patients compared to those from sleepiness in matched controls.

Narcoleptics

$\begin{array}{cr}148(82.2 \%)^{*} & 172(95.6 \%)^{*} \\ 116(78.4 \%) & 15(8.7 \%) \\ 73(49.3 \%) & 0(0.0 \%) \\ 69(46.6 \%) & 2(1.2 \%) \\ 57(38.5 \%) & 0(0.0 \%) \\ 38(21.1 \%)^{*} & 0(0.0 \%)^{*} \\ 19(10.6 \%)^{*} & 0(0.0 \%)^{*}\end{array}$

Presently working

Reduced performance

Fear of job loss

Earnings decreased

Prevented promotion

Job dismissal

Disability insurance

NS = nonsignificant $(p>.002)$ in this and subsequent tables.

* of 180 subjects 
Particularly bad accidents included a number of episodes of driving off the road embankment and demolishing the car, collision with a child on a bicycle, and hitting a motor cycle. No death of others was reported in any of the questionnaires.

\section{Accidents (other than driving)}

To the question "Have narcolepsy symptoms led to household or occupational accidents?", 88 (48.9\%) answered yes. By comparison only two controls $(1.8 \%)$ had had such accidents due to sleepiness. The patients' accidents were often quite serious. Cataplexy sometimes led to falling with bodily injury. Three patients answered that they fell asleep in the bath; in one this resulted in near drowning on several occasions. Others included running a hand through a washing machine wringer, falling asleep while repairing a roof and sliding off, and being injured by an automobile while walking half asleep across a street.
The question "Have narcolepsy symptoms led to smoking accidents?" was answered in the affirmative by 88 patients $(48.9 \%)$, whereas only 3 controls $(1.7 \%)$ had similar accidents from sleepiness. The high figure in narcoleptics is a conservative estimate, as the questionnaire unfortunately omitted to ask if the respondant was a smoker or not. It may therefore be assumed that well over one half of smoking narcoleptics have accidents related to smoking. Again some were potentially serious, including one instance of a bed fire.

\section{Recreation}

To the question "Do you obtain a good amount of exercise?", there was no significant difference between the number of affirmative answers for narcoleptics (76, i.e., $42.2 \%$ ) and controls (83, i.e., $46.6 \%$ ). To the question "Do you have trouble planning recreation?", 49 (27.4\%) narco-

\section{TABLE 2}

Driving effects attributed to narcolepsy symptoms in patients and to sleepiness in controls.

$\begin{array}{lccc} & \text { Narcoleptics } & \text { Controls } & \\ \text { Do you drive? } & 87(48.3 \%)^{*} & 113(62.8 \%)^{*} & \text { NS } \\ \text { Fell asleep driving } & 57(66.5 \%) & 7(6.2 \%) & \\ \text { Cataplexy driving } & 25(28.7 \%) & 0(0.0 \%) \\ \text { Sleep paralysis driving } & 16(11.5 \%) & 0(0.0 \%) \\ \text { Frequent near accidents } & 58(66.7 \%) & 0(0.0 \%) \\ \text { Led to accidents } & 32(36.8 \%) & 6(5.3 \%) \\ \text { Higher insurance } & 14(16.1 \%) & 1(0.9 \%) \\ \text { Suspended license } & 11(6.1 \%)^{*} & 7(3.9 \%)^{*} & \\ & & * \text { of } 180\end{array}$

TABLE 3

Frequency of falling asleep in various recreational activities in narcoleptics compared to controls.

\begin{tabular}{lcr} 
& Narcoleptics & \multicolumn{1}{c}{ Controls } \\
Watching entertainment & $162(90.0 \%)$ & $100(55.6 \%)$ \\
Playing cards & $73(40.5 \%)$ & $2(1.1 \%)$ \\
Swimming & $13(7.2 \%)$ & $1(0.6 \%)$ \\
Dancing & $8(4.4 \%)$ & $1(0.6 \%)$
\end{tabular}

leptics answered yes, as opposed to only $16(9.1 \%)$ normals. Both groups were asked if they had fallen asleep while engaged in various recreational activities. The results are presented in Table 3.

\section{Personality}

Eighty-seven (48.3\%) narcoleptics felt that their disease had been associated with personality changes, while such changes were attributed to sleepiness in only $5(2.9 \%)$ normals. Narcoleptics believed that the personality changes followed the onset of the condition in 83 of the $87(95.5 \%)$ and that they preceded the disease in the remaining $4(4.5 \%)$. Subjective assessments are outlined in Table 4. Furthermore, in a checklist of miscellaneous questions, subjects were asked if they had recurrent suicidal thoughts. Affirmative answers were much more common in narcoleptics (44, i.e., $24.6 \%$ ) than in controls $(9$, i.e., $5.0 \%)$. Some patients wrote that they had assumed a placid and withdrawn emotional state avoiding excitement or anger in order to avoid cataplexy. One stated "I now lack confidence. It makes life such a struggle". Several described effects of intense dreaming, nightmares, or hypnagogic hallucinations upon their psychological state. One wrote "It is sometimes difficult to separate them from reality".

\section{Interpersonal relationships}

The sleep attacks, chronic sleepiness and cataplexy often lead to negative reactions by others. To the question "Do you think others are understanding and tolerant of your symptoms?", $62(34.4 \%)$ answered no, and the remaining $118(65.6 \%)$ answered yes. Patients wrote that others thought they were bored, lazy, drunk, drugged, or not sick. Interpersonal relationships deteriorated because of sleep attacks or cataplexy during conversations, meals or even intercourse. Friends or relatives sometimes refused to accept their illness as such. Some were taken advantage of by the telling of jokes to provoke cataplexy. Several divorces were attributed to the condition. 


\section{Miscellaneous symptoms}

\section{Visual and Ocular}

The frequency of ocular and visual symptoms are compared in Table 5 .

\section{Memory}

Eighty-eight narcoleptic subjects $(48.9 \%)$ answered that their memory had worsened since the disease onset, 3 $(1.7 \%)$ that it had improved, 84 $(46.7 \%)$ that there was no change, and the remaining $5(2.8 \%)$ did not know. By comparison, 17 controls (9.4\%) noted poor memory due to sleepiness. Of the 88 patients, $68(81.0 \%)$ answered that memory problems were mainly for recent events, only 9 (10.7\%) mainly for remote events ("events of long ago"), and $7(8.3 \%$ ) for both. Subjects attributed memory problems to one or more of three possible categories on a checklist; poor concentration in $51(58.0 \%)$, sleep attacks in $41(46.6 \%)$, and excessive distractability in 24 (27.3\%). As noted above, the memory problems were believed to be a cause of job difficulties in $31.2 \%$ of working patients.

\section{Appetite}

Thirty-eight patients $(21.1 \%)$ answered that they ate more since developing narcolepsy, $21(11.7 \%)$ ate less, and the remainder $(67.2 \%)$ did not know.

\section{Sexual Life}

Questions in this area were optional. Nevertheless, 17 of the 112 male respondants (15.2\%) noted impotence, as opposed to only 4 controls (3.6\%). Subjects generally attributed the impotence directly to medication. Patients of both sexes (30 Ss, 16.7\%) noted a decrease in sexual drive since the onset of their narcolepsy, $3(1.7 \%)$ patients noted an increase, $2(1.1 \%)$ noted more erratic sexual drive, and the remaining large majority of patients $(145 \mathrm{Ss}, 80.6 \%)$ declined to answer. Controls noted a decrease in sexual drive attributable to sleepiness in only $9(5.0 \%)$, no change in 129 $(71.9 \%)$ and the remaining $42(23.3 \%)$ did not answer.
TABLE 4

Personality variables in narcoleptics compared to controls

\begin{tabular}{lccc} 
& Narcoleptics & Controls & \\
Recurrent depression & $92(51.1 \%)$ & $52(28.9 \%)$ & \\
Obsessive thoughts & $56(31.1 \%)$ & $37(20.6 \%)$ & \\
Large mood swings & $53(29.4 \%)$ & $43(23.9 \%)$ & NS \\
Manic excitement & $32(17.8 \%)$ & $21(11.7 \%)$ & \\
Had psychotherapy & $43(23.9 \%)$ & $17(9.4 \%)$ & \\
Believe extravert & $91(50.6 \%)$ & $83(49.1 \%)$ & NS \\
\multicolumn{1}{c}{ intravert $\quad$ don't know } & $76(42.2 \%)$ & $81(45.0 \%)$ & NS \\
& $13(7.2 \%)$ & $16(8.9 \%)$ & NS
\end{tabular}

TABLE 5

Visual symptoms in narcoleptics compared to controls

\begin{tabular}{|c|c|c|}
\hline & Narcoleptics & Controls \\
\hline Eye fatigue & $85(47.2 \%)$ & $74(41.1 \%)$ \\
\hline Defocusing & $58(32.2 \%)$ & $23(12.8 \%)$ \\
\hline Double vision & $54(30.0 \%)$ & $20(11.1 \%)$ \\
\hline Flickering of eyes & $44(24.4 \%)$ & $21(11.7 \%)$ \\
\hline $\begin{array}{c}\text { Fluorescent lights } \\
\text { bother eyes }\end{array}$ & $25(13.9 \%)$ & $37(20.6 \%)$ \\
\hline
\end{tabular}

TABLE 6

Miscellaneous somatic symptoms attributed to narcolepsy by patients compared to their frequency in controls.

$\begin{array}{lccc} & \text { Narcoleptics } & \text { Controls } & \\ \text { Excessive snoring } & 77(42.8 \%) & 31(17.2 \%) & \\ \text { Periodic imbalance } & 64(35.6 \%) & 28(15.6 \%) & \\ \text { Marked sensitivity to alcohol } & 57(31.7 \%) & 16(8.9 \%) & \\ \text { Very easily startled } & 49(27.2 \%) & 44(24.4 \%) & \text { NS } \\ \text { Sensations of hot and cold } & 42(23.3 \%) & 19(10.6 \%) & \\ \text { Buzzing or ringing in ears } & 30(16.7 \%) & 29(16.1 \%) & \text { NS } \\ \text { Sensations of unusual odours } & 10(5.6 \%) & 3(1.7 \%) & \\ \text { Sensations of unusual taste } & 5(2.8 \%) & 3(1.7 \%) & \text { NS }\end{array}$

\section{Menstrual Effects}

The premenstrual period was associated with an increase in symptoms in 15 of the 68 female patients $(22.1 \%)$, $1(1.5 \%)$ noted a decrease and the remainder did not know. However, 16 female controls $(23.5 \%)$ had an increase in sleepiness in the premenstrual period (NS). The menstrual period had increased symptoms in 11 patients $(16.2 \%)$, less frequent than for in- creased sleepiness in controls (22 Ss, $32.4 \%)$.

6. Somatic Symptoms

A checklist of a variety of somatic symptoms was provided. The results in decreasing incidence in narcoleptics are provided in Table 6 . As in the previous survey of narcoleptics (Broughton and Ghanem, 1976), the symptoms of excessive snoring and recurrent imbalance were the most frequent. 


\section{DISCUSSION}

It is evident that chronic excessive daytime sleepiness, recurrent microsleeps (the "momentary spells" of Ganado, 1958), sleep attacks, and cataplexy can seriously interfere with daily living. Other less widely recognized symptoms can also have such effects. Problems with vision can affect work, recreation, driving and other activities. These include blurring of vision, diplopia and ocular flickering. Diplopia with or without blurring has been reported by Kennedy (1929), Levin (1943), Keefe et al. (1960) and Chee (1968). Yoss et al. (1969) demonstrated pupillographic abnormalities during drowsiness in narcoleptics. Subjective ocular flickering might be due to partial REM sleep states with incomplete loss of consciousness during vivid hypnagogic hallucinations or sleep paralysis (Hishikawa, 1976; Vogel, 1976).

Subjective difficulty with memory was reported in about $50 \%$ of patients, mainly for recent events. Guilleminault and Dement (1977) have documented a deficit in recent memory for objects presented before series of microsleeps in such patients. The amnesic episodes of automatic behavior described as "fugue states" by Levin (1942), "fuguelike states" by Ganada (1958) and as "altered states of consciousness" by Guilleminault et al. (1965), can also be worrisome to these patients, due to loss of self-control.

Impotence in males or loss of libido in either sex can be serious problems. In some patients these may be complications of the REM suppressant medication used to control cataplexy, vivid hypnagogic hallucinations or sleep paralysis. Stimulant medication can lead to difficulties with pharmacists and with family and friends. Amphetamine psychosis can occur and was first reported in a narcoleptic patient (Young and Scoville, 1938). Snoring is common and may be bothersome. If it recurs in a loud, gutteral inspiratory form following a respiratory pause, it suggests the presence of sleep apnea, which is encountered not infrequently in narcolepsy (Cadhillac et al., 1971; Guilleminault et al., 1972).

Given the nature and persistence of symptoms, it is not surprising that narcolepsy has so many socio-economic effects. The quality of work lessens and becomes erratic giving rise to worry about losing a job, reduced earning capacity, lack of promotion, and actual job dismissal or enforced disability leave. Recreational activities become difficult to plan and are often restricted.

The high frequency of depression in this study and reported elsewhere (Roth and Nevsimalova, 1975) is of note. Coping with everyday life in the presence of chronic daytime sleepiness, sleep attacks, cataplexy and other symptoms becomes difficult. It is also possible that the pathophysiology of the disease may cause depression directly as abnormalities in nocturnal REM sleep are similar. Reduced REM latency or even direct sleep onset REM periods are observed in both endogenous depression (Kupfer, 1976) and narcolepsy-cataplexy (Rechtschaffen et al., 1962). Some have suggested that the symptoms themselves reflect psychological conflicts or needs (Barker, 1948; Levin, 1959; Cole, 1970). Such hypotheses, however, are difficult to reconcile with the well documented frequency of genetic transmission in idiopathic cases (Nevsimalova-Bruhova and Roth, 1972; Kessler et al., 1974; Baraitser and Parkes, 1978). A number of subjects attempted to avoid cataplexy by adopting a flat affect, a personality trait previously noted by Pond (1952) and by Sours (1963).

Educationally, narcoleptics reached university less frequently than controls, although the difference was not quite statistically significant. This is one of the few parameters differing from the earlier report of Broughton and Ghanem (1976) in which attainment of a university education was more common in narcoleptics. This difference may be due to the much smaller subject groups in the previous report, sampling errors, or other factors. In both studies narcolepsy seemingly caused poorer marks, social embarrassment and interpersonal problems.

A previous controlled study of driving in 105 narcoleptics compared to normals by Bartels and Kusakcioglu (1965) found that $40 \%$ of "narcoleptics" fell asleep at the wheel and $16 \%$ had resultant accidents. Our results indicate even greater driving problems (Table 2). This may be due to a difference in diagnostic criteria. In the Bartels and Kusakcioglu (1965) study, narcolepsy was defined simply as "irresistible sleepiness", whereas all of our patients also had one or several of the other major symptoms involving REM sleep. Their study undoubtedly included a number of patients with idiopathic hypersomnia or sleep attacks alone. In these conditions, the daytime attacks initially and mainly involve non-rapid eye movement (NR EM) sleep, which is less irresistible than attacks beginning with REM sleep and would allow more time for the driver to stop the car or otherwise avoid danger. On the other hand, in REM narcolepsy, at least $50 \%$ of sleep attacks begin with REM sleep: these are more abrupt in onset and more difficult to fight off. Moreover, cataplexy and sleep paralysis at the wheel are also obviously very dangerous. Unfortunately, the questionnaire did not differentiate the frequencies of sleep attacks or other symptoms at the wheel following diagnosis and treatment of the condition from those before. The very high rates of smoking, occupational and home accidents are also of note. Narcoleptics are obviously very prone to accidents and severe injury can result.

In summary, narcolepsy has frequent deleterious side effects and can be a truly debilitating chronic neurological condition emphasizing the importance of adequate diagnosis and treatment. Unfortunately, excessive daytime sleepiness, which is such an important factor in producing these effects, is also the most refractory symptom to treatment.

\section{ACKNOWLEDGEMENTS}

We thank Mr. J. Maru and Miss L. Gomberg for their technical and statistical support in this study. The study was supported by a grant from the Medical Research Council of Canada.

\section{REFERENCES}

BARAITSER, M. and PARKES, J.D. (1978). Genetic study of narcolepsy syndrome. J. Med. Genetics, 15:254-259. 
BARKER, W. (1948). Studies in epilepsy: personality pattern, situational stress and the symptoms of narcolepsy. Psychosom. Med., 10:193-202.

BARTELS, E.C. and KUSAKCIOGLU, O, (1965). Narcolepsy: a possible cause for automobile accidents. Lahey Clin. Found. Bull., 14:21-26.

BROUGHTON, R. and GHANEM, Q. (1976). The impact of compound narcolepsy on the life of the patient. In Narcolepsy, edited by C. Guilleminault, W.C. Dement and P. Passouant, pp. 201-219, Spectrum, New York.

BROUGHTON, R., GHANEM, Q., HISHIKAWA, Y,, SUGITA, Y., NEVSIMALOVA, S. and ROTH, B. (1981) The socioeconomic and related life-effects in 180 patients with narcolepsy from North America, Asia and Europe compared to controls. In The Physiological Basis of Sleep: Proceedings of the Third International Congress of Sleep Research, edited by I. Karacan. pp. 96-105 Noyes: Houston.

CADHILAC, J., TOMKA, R. and PASSOUANT, P. (1971). Les hypersomnies paroxystiques essentielles (interêt de la télémetrie). Rev. EEG Neurophysiol. (Paris), 1:309-313.

CHEE, P.H.Y. (1968). Ocular manifestations of narcolepsy. Br. J. Ophthalmol. 52:54-56.

COLE, L.E. (1970). Understanding human behavior, pp. 354-368. Chandler Press, Scranton, Pa.

DANIELS, L.E. (1934). Narcolepsy. Medicine (Baltimore), 13:1-22.

GANADO, W. (1958). The narcolepsy syndrome. Neurology (Minneap.), 8:487-492.

GUILLEMINAULT, C. BILLIARD, M., MONTPLAISIR, J. and DEMENT, W.C. (1975). Altered states of consciousness in disorders of excessive daytime sleepiness. J. Neurol. Sci., 26:377-393.
GUILLEMINAULT, C. and DEMENT, W.C (1977). Amnesia and disorders of excessive daytime sleepiness. In Neurobiology of Sleep and Memory, edited by R. Drucker-Colin and J.L. McGaugh, pp. 439-456. Academic Press: New York.

GUILLEMINAULT, C., ELDRIDGE, F. and DEMENT, W.C. (1972). Insomnia, narcolepsy and sleep apneas. Bull. Physiol. Pathol. Resp. (Nancy), 8:1129-1138.

HISHIKAWA, Y. (1976). Sleep paralysis. In Narcolepsy, edited by C. Guilleminault, W.C. Dement and P. Passouant, pp. 97-123. Spectrum: New York.

KEEFE, W.P., YOSS, R.E., MARTENS, T.G. and DALY, D.D. (1960). Ocular manifestations of narcolepsy. Amer. J. Ophthalmol., 49:953-958.

KENNEDY, A.M. (1929). A note on narcolepsy with a report of a case. Br. Med. J., 1:11121118

KESSLER, S., GUILLEMINAULT, C. and DEMENT, W.C. (1974). A family study of 50 REM narcoleptics. Acta Neurol. Scand., 50:503-512.

KUPFER, D.S. (1976). REM latency: a psychobiological marker for primary depression. Biol. Psychiatry, 11:159-174.

LEVIN, M. (1942). Mental symptoms of narcolepsy: forgetfulness and learning difficulty as manifestations of excessive inhibition of the highest cerebral centers. Am. J. Psychiatry, 98:673-675.

LEVIN, M. (1943). Diplopia in narcolepsy. Arch. Ophthalmol., 29:942-955.

LEVIN, M. (1959). Aggression, guilt and cataplexy. Am. J. Psychiatry, 116:133-136.

NEVSIMALOVA-BRUHOVA, S. and ROTH, B. (1972). Hered ofamilial aspects of narcolepsy and hypersomnia. Arch. Suisses Neurol. Neurochir. Psychiat., 100:45-54.
PASSOUANT, P. and BILLIARD, M. (1976). The evolution of narcolepsy with age. In Narcolepsy, edited by C. Guilleminault, W.C. Dement and P. Passouant, pp. 179196. Spectrum: New York.

POND, D.A. (1952). Narcolepsy: a brief critical review and study of eight cases. J. Ment. Sci., 98:595-604.

RECHTSCHAFFEN, A., WOLPERT, E., DEMENT, W., MITCHELL, S, and FISHER, C. (1962). Nocturnal sleep of narcoleptics. Electroencephalgr. Clin. Neurophysiol., 15:599-609.

ROTH, B. (1962). Narcolepsie and Hypersomnie vom Standpunkt der Physiologie des Schlafes. VEB Verlag Volk und Gesundheit: Berlin.

ROTH, B. and NEVSIMALOVA, S. (1955) Depression in narcolepsy and hypersomnia. Arch. Suisses Neurol. Neurochir. Psychiat., 116:291-300.

SOURS, J.A. (1963). Narcolepsy and other disturbances of the sleep/waking rhythm: a study of 115 cases with a review of the literature. J. Nerv. Ment. Dis., 137:525-542.

SPIEGEL, M.R. (1961). Theory and Problems of of Statistics, pp. 359. Schaum: New York.

VOGEL, G. (1976). Mentation reported from naps of narcoleptics. In Narcolepsy, edited by C. Guilleminault, W.C. Dement and P. Passouant, pp. 161-168. Spectrum: New York.

YOSS, R., MOYER, N. and OGLEK, K. (1969). The pupillogram and narcolepsy. A method to measure decreased levels of wakefulness. Neurology (Minneap.), 19:921-928.

YOUNG, D. and SCOVILLE, W.B. (1938). Paranoid psychoses in narcolepsy and the possible danger of benzedrine treatment. Med. Clin. North Amer., 22:637-646.

ZARCONE, V. (1973). Narcolepsy. N. Engl. J. Med., 288:1156-1166. 